\title{
Assessment of Knowledge, Attitude and Practice of Community Pharmacist towards the Provision of Pharmaceutical Care: A Community Based Study
}

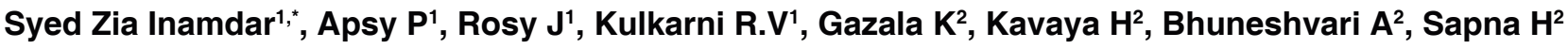 \\ 1'Department of Pharmacy Practice, BLDEA's SSM College of Pharmacy and Research Centre, Vijaypur 586 103, Karnataka, INDIA. \\ 2B Pharm, BLDEA's SSM College of Pharmacy and Research Centre, Vijaypur 586 103, Karnataka, INDIA.
}

\begin{abstract}
Background: The concept of pharmaceutical care was introduced in developed countries about three decades ago. Pharmaceutical care is the responsible provision of drug therapy for the purpose of achieving definite outcome which improve patient quality of life. Objective: To assess the Knowledge Attitude and Practice of community pharmacist in the deliverance of pharmaceutical care at community pharmacy level. Methodology: A survey study was conducted among various community dwelling pharmacies of Vijaypur city by administrating structured questionnaire to the working pharmacist to assess knowledge, attitude and practice in delivering pharmaceutical care. Result and Discussion: A total of 150 community pharmacies were surveyed in the study and hundred percent response rates was attained. There was a deficient knowledge $(66.66 \%)$ with respect to pharmaceutical care and pharmacists are reluctant in accepting the responsibility of addressing patient drug related needs owing to knowledge gap and just restricting themselves to traditional drug dispensing practices. The attitude component; $62.69 \%$ community pharmacist are of the opinion that practicing pharmaceutical care is resource intensive that is time consuming, requires more man power. On Practice $(70 \%)$ component; community pharmacist yearn to practice but they are deficient of adequate knowledge, attitude, resources and economics. Conclusion: There is deficit in knowledge and competence to practice pharmaceutical care among community pharmacist in the deliverance of Pharmaceutical health care.
\end{abstract}

Key words: Pharmaceutical care, Knowledge, Attitude, Practice, Community pharmacist.

\section{INTRODUCTION}

Globally, there have been significant changes in health care systems with respect to their quality and processes, and these have been specifically demonstrated in the practice of pharmacy. The traditional role of the pharmacist involving in the preparation, dispensing and selling of medications is no longer adequate. It signifies shift of practice in pharmacy from drug product-oriented to patient-oriented. The new approach has been given the name as pharmaceutical care. ${ }^{1}$ The concept of pharmaceutical care was introduced from US about three decades ago. This initiative becomes more dominant and effective part for thousands of pharmacist to practice it. It is implemented to obtain the maximum therapeutic benefits from the pharmacological treatments of the patient. ${ }^{2}$
In 1990, Hepler and strand published the first useful definition of pharmaceutical care. They wrote, "Pharmacentical care is the responsible provision of drug therapy for the purpose of achieving definite outcome which improve patient quality of life". These outcomes are (1) cure of a disease, (2) elimination or reduction of a patient's symptomatology, (3) arresting or slowing of a disease process, (4) preventing a disease or symptomatology. Pharmaceutical care is based on a relationship between the patient and the pharmacist who accepts responsibility for the patient. The concept implies the active participation of the patient in making decisions regarding his/her pharmacotherapy and the interdisciplinary cooperation of healthcare providers, and gives priority to the direct benefit of the
DOI: 10.5530/ijopp.11.3.34

Address for correspondence: Dr. Syed Zia Inamdar, Associate Prof and Clinical Pharmacist, Department of Pharmacy Practice, BLDEA's SSM College of Pharmacy and Research Centre, Vijaypur 586 103, Karnataka, INDIA.

Phone no: 9986666016 Email Id: syedzia.inamdar@ gmail.com

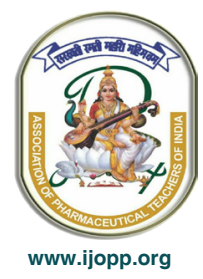


patient. Assessment of drug-related problems (DRPs), development of a care plan, its evaluation as and a continuous follow-up are important steps of the pharmaceutical care process. ${ }^{3}$ Patient expectations and desired quality of life are important factors to ensure the best possible medication outcome, and to possibly prevent recurrence of disease.

Pharmaceutical Care is a patient-centred, outcomes oriented pharmacy practice that requires the pharmacist to work in concert with the patient and the patient's other healthcare providers to promote health, to prevent disease, and to assess, monitor, initiate, and modify medication use to assure that drug therapy regimens are safe and effective. The goal of Pharmaceutical Care is to optimize the patient's health-related quality of life, and achieve positive clinical outcomes, within realistic economic expenditures. To achieve this goal, the following must be accomplished:

- A professional relationship must be established and maintained

- Patient-specific medical information must be collected, organized, recorded, and maintained

- Patient-specific medical information must be evaluated and a drug therapy plan developed mutually with the patient

- The pharmacist assures that the patient has all supplies, information and knowledge necessary to carry out the drug therapy plan

- The pharmacist reviews, monitors, and modifies the therapeutic plan as necessary and appropriate, in concert with the patient and healthcare team

Patients need pharmacist's services at the time they are receiving health care. Successful pharmacotherapy is specific for each patient. It includes individual drug therapy decisions; reaching an agreement between the patient and the health care provider on the therapeutic outcome - cure of a disease, elimination or reduction of a patient's symptoms, arresting or slowing a disease process or symptoms, and critical patient monitoring activities. For each individual patient's drug treatment, the pharmacist develops a care plan together with the patient. A systematic approach to patient care is illustrated in Figure 1.

Pharmacists are well suited to identify and resolve medication related problems and provide medication education to patients and their families to prepare them to manage medication therapy following discharge from hospitals. Such activities are fundamental to pharmaceutical care and are embodied in the 2015 goals of the American Society of Health-System Pharmacists. ${ }^{4}$

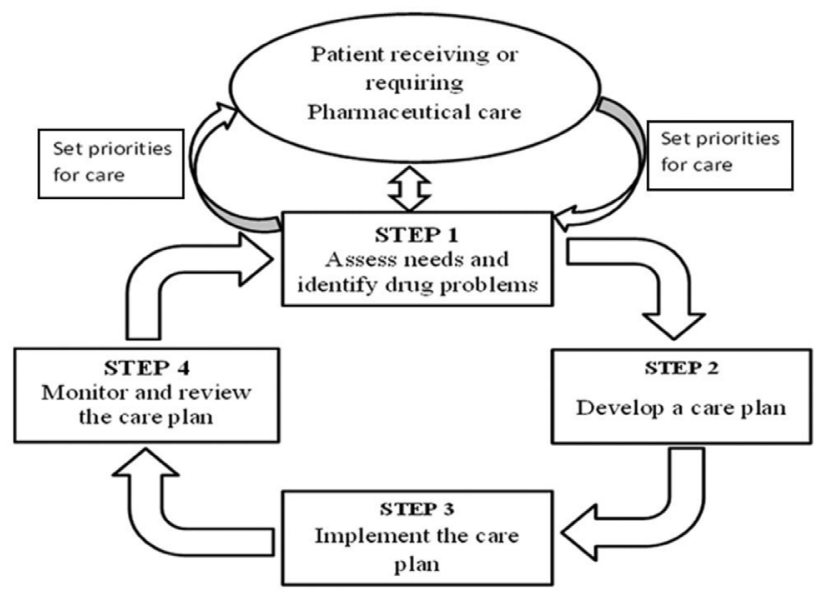

Figure 1: Systematic approach for pharmaceutical care ${ }^{5}$

The community pharmacy is a health care facility that emphasis providing pharmaceutical service to specific community. A registered pharmacist provides appropriate prescribed drugs to the consumer. Community pharmacist can act as a communicator with patients and other health care providers. The dispensing of drugs was used to be the only motto of community pharmacists in earlier time. But currently, they have been identified to play an extended role to provide clinical care directly to the patients as a part of health care professional responsibility. In contrast to many other countries, community pharmacies and pharmacists in the US are regulated by individual states and prescription drugs must be dispensed through license pharmacies. Community pharmacies are not geographically restricted market place factors to determine their number and location. At the time of dispensing it is mandatory to provide instruction for drug use and they should also counsel those receiving new prescription. In early 2000 study $2 / 3^{\text {rd }}$ of pharmacies provided counselling for new prescription and performs several other activities other than dispensing. Pharmacists tend to be more disease state focus when counselling. Several cognitive activities were performed in many states of US. They include pharmaceutical care, medication therapy and management services, medication reviews, resolution of drug released problems and pharmaceutical care management. ${ }^{6}$

Nowadays, pharmaceutical care has become a dominant form of practice for thousands of pharmacists all over the world. However, for the patients and pharmacists in India, this concept remains either unknown or in dormant state due to its lesser or no adoption in routine practice, and to a greater extent pharmacists especially community pharmacists were not aware of the concept. In India, pharmacists had a little role in the healthcare services. The management of patient's therapy is managed by physicians with the help of nursing facilities thus 
leading to underutilization of services and knowledge of pharmacists. Physicians, who are unfamiliar with services of pharmacists, may be declined to give authority to less qualify as perceived. When compared to developed countries, here the system is too different. India face significant problem in provision of medication care. Clinical pharmacy service has been neglected or it is at its infancy stage so far. It is the limit to accept pharmacist to have clinical role to overcome the dismal promising changes that are undergoing. Nowadays many hospitals across India have of late initiated clinical pharmacy and pharmaceutical care services and this imitative has a long way to go in order to witness its positive outcomes. Indian community pharmacy is limited to drug dispensing; it mainly focused on selling of drugs. The guidelines of WHO suggested GPP (Good Pharmacy Practice) emphasize the provision of pharmaceutical care and National Standard should be set for promotion of health. ${ }^{7}$ Independent pharmacies in developing nations can play an important role in reducing morbidity and mortality, providing continuity of care, and improving life expectancy. ${ }^{8}$ Provision of pharmaceutical care, complete documentation of pharmacotherapy process, and achieving cost effective use of resources ultimately lead to formation of a comprehensive health care system. A positive mutual relationship with all healthcare professionals is beneficial for patient's outcomes. The patients visit retail pharmacies often to buy the prescribed medicines. Retail pharmacy is best suited to provide the individualized patient care by providing patient counselling, reviewing of prescriptions, detection of potential side effects etc. Pharmacists are in a position to communicate any therapy-related information to the physician so that he can adopt appropriate correction to the therapy. It is important to Emphasize the fact that pharmaceutical care is aimed to achieve rational and evidence-based pharmacotherapy, which is beneficial for patient and society. ${ }^{2}$

India needs sustainable, high quality human resources for health with a variety of skills and who are adequately distributed in all states, particularly in rural areas. ${ }^{9}$ The public health system has a shortage of medical and para medical personnel. Government estimates indicate that $16 \%$ are without a pharmacist. Hence, there is a need to develop a national human resource policy, which examines the creation and establishment of cadres of trained healthcare professionals who can provide leadership and direction to the health sector to meet global standards. It should also make use of available pharmacists and train them in the pharmaceutical care area leading to sustainable human resource for the health and pharmaceutical care delivery. Within the present context the study is an attempt to evaluate Pharmaceutical
Care Knowledge, Attitude and Practice [KAP] of community pharmacist and extent of its implementation and related barriers in its deliverance at community/ societal level in Vijaypur city.

\section{MATERIALS AND METHODS}

A prospective survey study was conducted by administrating structured questioner prepared by reviewing literature on pharmaceutical care to working community pharmacists among various community pharmacies spread within Vijaypur city. A total of 150 Pharmacist from surveyed community pharmacies were interviewed to collect data with respect to KAP. The questionnaire was structured in a way to obtained data with respect to; Section 1 - Demographic characteristics, Section 2 - Knowledge on pharmaceutical care practice, Section 3 - Attitude towards the practice of pharmaceutical care, Section 4 - Pharmaceutical care practice, Section 5 - Barriers to implementation of pharmaceutical care. Descriptive statistics was used to summaries the data and organize them into groups according to the sections of the questionnaires. It was designed also using to point like response format consisting of yes and no and a few open ended questions.

\section{RESULTS}

A total of 150 pharmacists were interviewed out of which 149 completed the survey giving a response rate of $99.99 \% .99 .33 \%$ respondents were males while female accounts for $0.66 \%$. Majority of the respondents [62\%] were having a work experience of within 1-10 years. (Table 1). $79.33 \%$ of respondents offered advice and counselling during dispensing. 66.66\% defined pharmaceutical care as dispensing of medication to patient only. $68.66 \%$ feels review of patient's drug therapy and secondary changes to prescription were necessary, and $84 \%$ agree that pharmacists should take full responsibility of drug related needs of patients. However, $84.66 \%$ shares pharmaceutical care as a responsibility of pharmacists to dispense and counsel on drugs prescribed by the physician (Table 2).

On attitude to practice of pharmaceutical care, $62.66 \%$ of respondent's feels PC is a mandate of pharmacist only, $78 \%$ see it as a primary responsibility of pharmacist only. High proportions $93 \%$ are of the belief that pharmaceutical care is a valuable mode of practice and will serve to improve patients health needs. $81 \%$ agrees that practicing pharmaceutical care in community pharmacies will increase patient's confidence in the profession and enhance pharmacy practice. While $42 \%$ 
Table 1: Demographic Data of Respondents.

\begin{tabular}{ccc}
$\begin{array}{c}\text { Characteristics } \\
(\mathbf{n = 1 5 0 )}\end{array}$ & $\begin{array}{c}\text { No of } \\
\text { respondents }\end{array}$ & Percentage (\%) \\
\hline \multicolumn{3}{c}{ Gender } \\
Male & 149 & 99.33 \\
Female & 1 & 0.66 \\
\multicolumn{2}{c}{ Year of Experience (in years) } \\
$11-10$ & 93 & 62 \\
$21-30$ & 38 & 25.33 \\
$\geq 31$ & 16 & 10.67 \\
\end{tabular}

Table 2: Distribution of Knowledge on Pharmaceutical Care Services.

\begin{tabular}{|c|c|c|c|}
\hline $\begin{array}{l}\text { S. } \\
\text { No. }\end{array}$ & $\begin{array}{c}\text { Pharmaceutical care } \\
\text { service }\end{array}$ & $\begin{array}{c}\text { Agree } \\
(\%)\end{array}$ & $\begin{array}{l}\text { Disagree } \\
(\%)\end{array}$ \\
\hline 1. & $\begin{array}{c}\text { Do you dispense medication } \\
\text { to patients only? }\end{array}$ & $100(66.66)$ & $50(33.4)$ \\
\hline 2. & $\begin{array}{l}\text { Do you offer the advice } \\
\text { and counsel during drug } \\
\text { dispensing? }\end{array}$ & 119(79.33) & $31(20.7)$ \\
\hline 3. & $\begin{array}{l}\text { Do you offer advice to } \\
\text { patients only? }\end{array}$ & $112(74.66)$ & $38(25.4)$ \\
\hline 4. & $\begin{array}{l}\text { Is the pharmacist only } \\
\text { responsible is to dispense and } \\
\text { counsel the patients on drug } \\
\text { prescribed the physician's. }\end{array}$ & $127(84.66)$ & $23(15.4)$ \\
\hline 5. & $\begin{array}{l}\text { Do you review patient's } \\
\text { drug therapy and secondary } \\
\text { changes where necessary? }\end{array}$ & $103(68.66)$ & $47(31.4)$ \\
\hline 6. & $\begin{array}{l}\text { Do you review patient's } \\
\text { drug therapy and secondary } \\
\text { changes where necessary? }\end{array}$ & $126(84)$ & $24(16)$ \\
\hline 7. & $\begin{array}{l}\text { Are the pharmacists } \\
\text { accountable for their } \\
\text { professional conduct? }\end{array}$ & 134(89.33) & $16(10.66)$ \\
\hline
\end{tabular}

are of the opinion that practicing pharmaceutical care is resource intensive that is time consuming, requires more man power and is not worth the trouble. $82.66 \%$ believes in order to assure themselves a place in health care team, community pharmacist must practice pharmaceutical care (Table 3).

On practice of respondents to pharmaceutical care, $70 \%$ of community pharmacist collects information from patients before dispensing prescribed drug. $84.7 \%$ normally identifies prescription problems. $48.7 \%$ had a case of adverse drug reactions report by patients while $68.3 \%$ of agree that changing of prescribed medication is a part of pharmaceutical care (Table 4).
Table 3: Community Pharmacist's Attitude towards Practice of Pharmaceutical Care.

\begin{tabular}{|c|c|c|c|}
\hline S. No. & Attitude & $\begin{array}{c}\text { Agree } \\
(\%)\end{array}$ & $\begin{array}{c}\text { Disagree } \\
(\%)\end{array}$ \\
\hline 1. & $\begin{array}{l}\text { Does pharmaceutical } \\
\text { care is a mandate of } \\
\text { pharmacist only }\end{array}$ & $94(62.66)$ & $56(37.4)$ \\
\hline 2. & $\begin{array}{l}\text { Do you think the } \\
\text { primary responsibility } \\
\text { of pharmacists in } \\
\text { general and community } \\
\text { pharmacists is to provide } \\
\text { pharmaceutical care? }\end{array}$ & $117(78)$ & $33(22)$ \\
\hline 3. & $\begin{array}{l}\text { Does pharmaceutical care } \\
\text { is a valuable mode of } \\
\text { practice and which serve } \\
\text { to improve patient health } \\
\text { outcomes. }\end{array}$ & $140(93.33)$ & $10(6.7)$ \\
\hline 4. & $\begin{array}{l}\text { Do you think practicing } \\
\text { of pharmaceutical health } \\
\text { care in community } \\
\text { pharmacies will increase } \\
\text { patients confidence in the } \\
\text { profession and enhance } \\
\text { pharmacy practice }\end{array}$ & $125(83.33)$ & $25(16.7)$ \\
\hline 5. & $\begin{array}{c}\text { Do you think continuous } \\
\text { pharmaceutical education } \\
\text { is necessary for } \\
\text { community pharmacists to } \\
\text { practice pharmaceutical } \\
\text { care? }\end{array}$ & $143(95.33)$ & $7(4.7)$ \\
\hline 6. & $\begin{array}{c}\text { In order to assure } \\
\text { themselves a place } \\
\text { in health care team, } \\
\text { community pharmacists } \\
\text { must practice } \\
\text { pharmaceutical care }\end{array}$ & $124(82.66)$ & $26(17.4)$ \\
\hline 7. & $\begin{array}{l}\text { Do you think by practicing } \\
\text { pharmaceutical care is too } \\
\text { resource intensive, time } \\
\text { consuming and requires } \\
\text { more man power. }\end{array}$ & $63(42)$ & $87(58)$ \\
\hline
\end{tabular}

Table 4: Community Pharmacist's Pharmaceutical Care Practices.

\begin{tabular}{|c|c|c|c|}
\hline S. No. & Practice & $\begin{array}{c}\text { Agree } \\
(\%)\end{array}$ & $\begin{array}{c}\text { Disagree } \\
(\%)\end{array}$ \\
\hline 1. & $\begin{array}{l}\text { Do you collect medication/ } \\
\text { medical data from your } \\
\text { patients? }\end{array}$ & $105(70)$ & $45(30)$ \\
\hline 2. & $\begin{array}{l}\text { Do you able to identify } \\
\text { problems/errors in } \\
\text { prescription order? }\end{array}$ & $127(84.7)$ & $23(15.4)$ \\
\hline 3. & $\begin{array}{c}\text { Have you had any reported } \\
\text { cases of ADR'S by your } \\
\text { patients? } \\
\text { Have you had any reported } \\
\text { cases of ADR'S by your } \\
\text { patients? }\end{array}$ & $73(48.7)$ & $77(51.4)$ \\
\hline 4. & $\begin{array}{l}\text { As a pharmacist to you } \\
\text { think changing of prescribed } \\
\text { medication is part of } \\
\text { pharmaceutical care? }\end{array}$ & $104(69.3)$ & $46(30.7)$ \\
\hline
\end{tabular}




\begin{tabular}{|c|c|c|c|}
\hline S. No. & Barriers & Agree (\%) & Disagree (\%) \\
\hline 1. & $\begin{array}{l}\text { Poor relationship with } \\
\text { Physician. }\end{array}$ & 101(67.33) & $49(32.66)$ \\
\hline 2. & $\begin{array}{c}\text { The current curriculum } \\
\text { education is inadequate } \\
\text { to practice }\end{array}$ & $69(46)$ & $81(54)$ \\
\hline 3. & $\begin{array}{l}\text { Lack of training in } \\
\text { pharmaceutical care. }\end{array}$ & $99(66)$ & $51(34)$ \\
\hline 4. & Lack of confidence. & $50(33.33)$ & $100(66.66)$ \\
\hline 5. & Lack of space. & $62(41.33)$ & $88(58.66)$ \\
\hline 6. & Lack of privacy. & $60(40)$ & $90(60)$ \\
\hline 7. & $\begin{array}{l}\text { Improper design of } \\
\text { community pharmacy. }\end{array}$ & $67(44.66)$ & $83(55.33)$ \\
\hline 8. & $\begin{array}{l}\text { Attitude towards } \\
\text { counseling. }\end{array}$ & $56(37.33)$ & $94(62.66)$ \\
\hline 9. & Others & $11(7.33)$ & 139(92.66) \\
\hline
\end{tabular}

On barriers to implementation of pharmaceutical care, $67.33 \%$ agrees that poor relationship of community pharmacists with other health care members is one of the major barriers while $33.33 \%$ agrees to the fact that lack of confidence in pharmacists themselves is the reason. $66 \%$ agrees that lack of train personnel and support staff needed to offer pharmaceutical care is a barrier. (Table 5)

\section{DISCUSSION}

Of all the pharmacists reviewed, the pioneer question asked was whether they know the word pharmaceutical care or not, $30 \%$ shows positive answer while $70 \%$ shows negative although they practice components of pharmaceutical care, they are not familiar with the word pharmaceutical care. Around $9.33 \%$ of the people show lack of knowledge about pharmaceutical care attributing to diminutive continuing pharmacy education programme, lack of constant update in the field of pharmacy profession, non-pharmacy back ground work force in pharmacies. $70 \%$ of people show positive attitude towards 'Attitude of Pharmaceutical care' and practice pharmaceutical care but $30 \%$ do not practice as they aimed at only dispensing and marketing aspect of community pharmacies, the reasons for not practicing are attributed to lack of information and inadequate education with respect to professional pharmaceutical care practice.

In the present study male respondents were higher than female respondents which are more or less in similarity to studies reported from the developed world, where there is a relationship between gender and attitude to good pharmacy practice, male pharmacist had better attitude towards good pharmacy practice than female as observed in the study owing to random distribution of genders among community pharmacies. ${ }^{10}$ The highest years of professional experience of which $61.33 \%$ of the respondents fell within 0-10 years (Table 1) are the young generation pharmacists who are more knowledgeable and form the major determinant of workforce. The respondents had a knowledge deficit of pharmaceutical care concept, $79.33 \%$ of the respondent's defined pharmaceutical care as pharmacists offering advice and counselling during drug dispensing only, while $66.66 \%$ defined it as dispensing of medication only. However, according to a WHO which highlighted that the role of pharmacist as an active member of the healthcare teams both in hospital and community pharmacy. It showed that there is a need for continued mandatory pharmacy practice education for all community pharmacists. ${ }^{11}$

The present study showed that community pharmacists have a positive attitude towards pharmaceutical care similar to study reported by Cordin $\mathrm{M}$ et al. and Ismail AS et al. which evaluated community Pharmacists attitude towards professional practice in republic of Moldova and in Nigeria, Pharmacists in appear to be deeply rooted in traditional practice of dispensing and counselling and are distant from practice such as Pharmaceutical care, drug information and self-care, ${ }^{12}$ but found the attitude of respondents to practice pharmaceutical care to be favourable, ${ }^{13}$ quite comparable with Indian scenario.

In the present study the respondents were asked about the barriers to the implementation of pharmaceutical care, $33.33 \%$ of respondents agreed that lack of confidence by pharmacist themselves play a major role, while $67.33 \%$ agreed that poor relationship of community pharmacist with other health care providers along with perceived notion of denying authority to lesser qualification also played the role and $66 \%$ sees lack of trained personnel and support staff to offer pharmaceutical care as the major barrier to its implementation. The study was similar in line with another carried out in northwest China were the community pharmacists reported lack of time, information, skills and support from other health professionals and economic issues as the barrier to the provision of Pharmaceutical Care Services. ${ }^{14}$

\section{CONCLUSION}

The survey study revealed deficit in knowledge and practice of pharmaceutical care among community pharmacists. There is also a lack of competence to practice pharmaceutical care. Pharmacist's advancing role in improving patients care demands attention from 
regulatory bodies to implement policies and guidelines to empower community pharmacists for the deliverance and provision of pharmaceutical care at community setting.

\section{ACKNOWLEDGEMENT}

The authors are thankful to the management of BLDE association for supporting the work.

\section{CONFLICT OF INTEREST}

The authors declare no conflict of interest.

\section{ABBREVIATIONS}

US: United States, DRPs: Drug Related Problems, WHO: World Health Organization, GPP: Good Pharmacy Practice, KAP: Knowledge, Attitude and Practice, ADRs: Adverse Drug Reactions.

\section{SUMMARY}

Community Pharmacist's in Indian health care setting are appropriately place in the overall drug use and patient care process. But, they lack competency to practice core pharmaceutical care services. The observation is evident to the vast scope for mandatory pharmacy practice education for all community pharmacists in the optimum delivery of pharmaceutical care.

\section{REFERENCES}

1. Tumkur A, Muragundi PM, Shetty R, Naik A. Pharmaceutical care: Need of the hour in India. J Young Pharmacists. 2012;4(4):282-6.

2. Berenguer $B$, et al. Pharmaceutical care: Past, present and Future review article. Curr Pharm Des. 2004.

3. Hepler CD, Strand LM. Opportunities and responsibility in pharmaceutical care. Am J Hosp Pharm. 1990;47:533-43.

4. American Society of Health-System Pharmacists. 2015 Health- System Pharmacy Initiative. Available from: http://www.ashp.org/2015. [Last accessed on 2010 Oct 15].

5. Counselling and advice on medicines and appliances in community pharmacy practice. Clinical Resource and Audit Group. Edinburgh: The Scottish Office, NHS in Scotland; 1996.

6. Chirstensen DB, Farris KB. Pharmaceutical care in community Pharmacies: Practice and Research in the U.S.

7. Sreelalitha N, Vigneshwaran E. Review of Pharmaceutical care services provided by the pharmacists. RDT Hospital, Bathalapally, Anatapur AP India

8. Patel I, Chang J, Srivatsa J, Balkrishnan R. Mortality in the developing world Can pharmacists intervene?. Indian J Pharm Pract. 2011;4(2):1-9.

9. Rao M, Rao KD, Shivakumar AK, Chaterjee M, Sundararaman T. Human resources for health in India. Lancet. 2011;377(9765):587-98.

10. Hanafi S, Poormalek F, Torakamandi H, Hajimiri M, Esmaeili M, Khooie SH, et al. Evaluation of Community Pharmacists' Knowledge, Attitude, and Practice towards Good Pharmacy Practice in Iran. J of Pharm Care. 2013;1(1):19-24.

11. www.who.int/medicinedocs/pdf/wh. The Role of the pharmacist in self-care and self-medication

12. Cordin M, Safta V, Ciobanu A, Sautenkova N. An assessment of community pharmacist's attitude towards professional practice in the Republic of Moldova. Pharmacy Practice. 2008;6(1):1-8.

13. Ismail AS, Oluwatoyin O. Pharmaceutical care implementation: A survey of attitude perception and practice of pharm. In ogun state southwestern Nigeria. Intern Journal of Health Research. 2011;4(2):91-97.

14. Fang $\mathrm{Y}$, Yang $\mathrm{S}$, Feng $\mathrm{B}$, Ni $\mathrm{Y}$, Zhang $\mathrm{K}$. Pharmacists' perception of pharmaceutical care in community pharmacy: a questionnaire survey in North West China. Health Soc Care Community. 2001;19(2):189-97. 